\title{
Evaluation of Selecting Building Structure Construction Method
} Ibrahim alhammad

\begin{abstract}
There ai-e basically two construction methods used in using reinforced concrete as a building structures, the first is by applying ready mix concrete in the job site and the second is by utilizing precast concrete.

This paper aims at comparing and contrasting the costs of the structural elements, in Riyadh city, of building structure for the above two construction methods. The components of building structure selected for the sake of comparison in this study are: Foundations, Columns, slabs, beams and stairs. Two similar buildings in function, design criteria, area of floors, other features and total costs; with the exception that the two structures are designed in two different types: the first is using ready mix concrete and the second using pecast concrete. The results of this study, given the size and location of the two projects, calls for constructing building structure using construction method of ready mix concrete over using precast for economic reasons.
\end{abstract}

